\title{
O GROTESCO NO CINEMA - POR UM VISIONAMENTO BAKHTINIANO GROTESQUE IN CINEMA - FOR A BAKHTINIAN APPROACH
}

\author{
Alexandre Silva Guerreiro \\ Universidade Federal Fluminense - UFF \\ alexandreguerreiro@hotmail.com
}

\begin{abstract}
RESUMO. 0 conceito de grotesco apresenta um longo desenvolvimento, desde o Romantismo do século XIX, até os escritos de Bakhtin que atrelam sua essência à cultura popular. A existência de vertentes diversas, como o grotesco realista e o grotesco romântico, nos convida a pensar de que maneira esse conceito vem se transformando para, em seguida, abordar a sétima arte através de uma visão panorâmica que nos permita afirmar a presença de um cinema do grotesco, bem como diferenciar qual tipo de grotesco está presente em cada filme, abrindo novas possibilidades de leitura da arte cinematográfica.

PALAVRAS-CHAVE: Bakhtin; Cinema; Grotesco Realista; Grotesco Romântico.
\end{abstract}

ABSTRACT. The concept of grotesque presents a long development, from Romanticism of century XIX, to the writings of Bakhtin that link its essence to the popular culture. The existence of different slopes, such as the realistic grotesque and the romantic grotesque, invite us to think in what way this concept has been transformed and how we can approach the seventh art with a panoramic view that allows us to affirm the presence of a grotesque cinema, as well as differentiate what kind of grotesque is present in each film, opening new possibilities for reading the cinematographic art.

KEYWORDS: Bakhtin; Cinema; Realism Grotesque; Romantic Grotesque.

Abordar a conceituação do grotesco, ou mesmo promover uma primeira aproximação com o tema através de seus principais textos, cumpre, aqui, uma função fundamental: ressaltar a existência de diversos grotescos para melhor definir o grotesco bakhtiniano. Para isso, é importante revisitar algumas manifestações do grotesco, elencando as possibilidades de interpretação do conceito para, então, chegarmos ao grotesco que tomamos como ferramenta conceitual em nossa análise fílmica.

Este artigo se dividirá em dois momentos: de início, procuraremos mapear algumas categorias relevantes do grotesco a partir de seus principais pensadores; em seguida, faremos uma aproximação entre o grotesco e o cinema, construindo um panorama do que entendemos como grotesco cinematográfico. 
Pretendemos, assim, aglutinar uma série de filmes que se aproximam a partir de uma análise que use como chave conceitual, sobretudo, o grotesco bakhtiniano. Seria possível, através disso, afirmar a existência de uma tradição do grotesco no cinema? De que maneira os filmes traduzem, estética e eticamente, o conceito do grotesco que utilizamos? Os diversos exemplos de filmes que elencaremos em nossa análise nos ajudam a pensar na relevância desse grotesco cinematográfico. Para isso, faz-se necessária uma explanação do grotesco como conceito, sua origem e suas vertentes.

Victor Hugo, Wolfgang Kayser, Mikhail Bakhtin e, no Brasil, mais expressivamente, Muniz Sodré, são os autores com obras dedicadas ao conceito do grotesco. Nesses autores, observamos uma preocupação em aprofundar uma abordagem do conceito, na qual, nem sempre, fala-se do mesmo grotesco. A seguir, vamos delinear as transformações, pelas quais o conceito passou, apontando as considerações de cada autor acerca do(s) grotesco(s).

\section{Considerações sobre o(s) grotesco(s)}

Victor Hugo teorizou sobre o grotesco ${ }^{1}$ ainda no século XIX, mais precisamente em 1827, ao escrever o prefácio de uma peça teatral, a saber, Cromwell. Ao discorrer sobre a modernidade do drama, Victor Hugo deixou registrado um verdadeiro tratado acerca do grotesco e do sublime, embora esse prefácio contenha uma duvidosa divisão da história da humanidade, pouco aceita, que reduz a experiência humana a três tempos vinculados à poesia que, também, se manifestaria em três idades². Foi mesmo na sua explanação sobre o grotesco que figurou o maior interesse sobre essa obra.

0 grotesco romântico é característico do drama moderno e busca, incessantemente, minar a estética clássica. A tradição do classicismo é minada, inclusive, pelo cristianismo profundamente presente em Hugo. Nas palavras do autor:

\footnotetext{
10 termo grotesco tem origem no séc. XV, quando "Escavações feitas em Roma nos subterrâneos das Termas de Tito trazem à luz um tipo de pintura ornamental até então desconhecida. Foi chamada de "grotesca", derivado do substantivo italiano "grotta" (gruta)." (BAKHTIN, 2013, p. 28)

2 A divisão apontada por Victor Hugo seria a seguinte: a poesia teria figurado nos tempos primitivos com o lirismo, nos tempos antigos, com a epopeia, e nos tempos modernos, com o drama.
} 
[...] não há nada de tão material como a teogonia antiga. Longe de ela ter pensado, como o cristianismo, em separar do corpo o espírito; ela dá forma e fisionomia a tudo, ainda às essências, ainda às inteligências. Tudo nela é visível, palpável, carnal. (HUGO, 1988, p. 21-22).

Hugo preocupa-se em valorizar categorias dicotômicas, cristianismo e classicismo, corpo e espírito. Podemos notar o dualismo que servirá de base para os conceitos de sublime e de grotesco, colocados em posição de antagonismo por Hugo.

[...] a musa moderna verá as coisas com um olhar mais elevado e mais amplo. Sentirá que tudo na criação não é humanamente belo, que o feio existe ao lado do belo, o disforme perto do gracioso, o grotesco no reverso do sublime, o mal com o bem, a sombra com a luz (HUGO, 1988, p. 25).

Para Hugo, a marca da modernidade é o drama, e a presença do grotesco ao lado do sublime, uma prova da evolução da arte. A Antiguidade, afirma o autor, não teria feito A Bela e a Fera. É bom lembrar que, da mesma forma, somente o espírito moderno permitiu que o próprio Hugo desenhasse na literatura o corcunda Quasímodo, encerrado na torre da Catedral de Notre-Dame, servindo como ícone da sublimação do grotesco promovida pelo seu criador.

A propósito do grotesco romântico, é preciso salientar que não se trata de um grotesco provocador do riso, regenerador, alegre. O grotesco romântico está impregnado de horror, espanto e melancolia. A elaboração conceitual de Hugo acerca do grotesco é feita a partir desse contraponto com o sublime. Este, por sua vez, nos remete à ideia de belo que, desde a Grécia Antiga, passou por muitas transformações, que fogem às possibilidades de alcance desse artigo. Porém, vale registrar que é a partir de Kant que o belo se torna uma categoria estética, enquanto objeto de uma satisfação livre de qualquer interesse ${ }^{3}$.

Sob outra perspectiva, encontramos o grotesco de câmara. Mas seria possível que esse grotesco fosse confundido com o grotesco romântico? É o próprio Bakhtin quem faz essa correlação: "o grotesco romântico é um grotesco de câmara, uma

\footnotetext{
${ }^{3}$ Naturalmente, isso deveria ser aprofundado se o belo fosse nosso objeto de estudo, já que em Kant o belo foi analisado e conceituado a partir da qualidade do julgamento do gosto, da quantidade, de sua relação com um fim e da modalidade desse julgamento, desembocando na idéia do belo como categoria estética, desvinculada das outras formulações que o belo recebia na Antiguidade.
} 
espécie de carnaval que o indivíduo representa na solidão, com a consciência aguda de seu isolamento" (BAKHTIN, 2013, p. 33).

Na verdade, Bakhtin utiliza o grotesco romântico em oposição à categoria do realismo grotesc $\mathrm{O}^{4}$. Assim, ele deixa de registrar que toda a explanação de Kayser, que engloba o grotesco romântico e, também, o grotesco realista, que serve ao próprio Bakhtin, está incluída no que se pode chamar de um grotesco de câmara. Kayser toma o referencial do grotesco na arte, notadamente na pintura, e é isso que faz com que sua explanação seja assim considerada, o que não foi observado por Bakhtin.

Não se trata, portanto, de tomar o grotesco romântico como sendo um grotesco de câmara, como afirma Bakhtin. Em Kayser, as diversas categorizações do grotesco se inserem dentro de uma mesma abordagem da arte, o que nos faz associar o grotesco analisado por Kayser como sendo um grotesco de câmara, seja o romântico, seja o realista.

Entre Hugo e Kayser, mais de um século se passou. Outros autores, nesse intervalo, tangenciaram o tema ${ }^{5}$. Em 1957, Kayser tentou preencher essa lacuna de um século na qual a conceituação do grotesco havia ficado em suspenso. Seu livro $O$ Grotesco surge da sua inquietação diante da pintura, mais especificamente quando da sua primeira visita ao Museu do Prado, quinze anos antes do lançamento do livro. De maneira esquemática, Kayser busca responder diversas questões, desde a conceituação do grotesco até a ampliação do conceito e sua definição dentro do romantismo do séc XIX e da época moderna.

Kayser promove um avanço em relação às especulações de Hugo. Sua pesquisa tenta detectar, no seio da tradição cultural ocidental, uma categoria estética não reconhecida. Assumindo uma perspectiva histórica, Kayser salienta que o fenômeno do grotesco é mais antigo que seu nome, observando que uma "história completa do grotesco deveria compreender a arte chinesa, etrusca, asteca, germânica antiga e

\footnotetext{
${ }^{4}$ Cabe salientar que Bakhtin faz uma distinção entre o realismo grotesco, próprio da Idade Média e do Renascimento, e o grotesco realista, que teria surgido já no século XX. Este assumiria as mesmas características daquele. A distinção apontada por Bakhtin é meramente temporal.

${ }^{5}$ Bakhtin aponta, entre outros, Nietzsche, Baudelaire, Gautier e Schlegel, esse último antes de Hugo.
} 
outras mais, do mesmo modo que a literatura grega (Aristófanes!) e outras manifestações poéticas". (KAYSER, 1986, p. 17)

No entanto, Bakhtin faz uma severa crítica ao arsenal teórico de Kayser por julgar insuficientes as observações deste sobre a essência do grotesco. "Kayser propôs-se a escrever uma teoria geral do grotesco, a revelar a própria essência do fenômeno (...) razão pela qual ele o compreende e aprecia de uma forma um pouco desvirtuada." (BAKHTIN, 2013, p. 41).

O grotesco de câmara, como afirmamos acima, não pode ser usado como sinônimo do grotesco romântico já que a abordagem de Kayser privilegia também outras manifestações do conceito. Em sua análise, Kayser cria uma taxonomia do grotesco a partir da própria divisão dos capítulos. Assim, discorre sobre o grotesco romântico, o grotesco realista, o grotesco fantástico, o grotesco da linguagem, até chegar aos surrealistas. Aliás, para Kayser, a arte gráfica é a forma mais apropriada para a representação do grotesco.

Ao promover uma valorização do gênio de Rabelais, Bakhtin redefine o conceito de grotesco se comparado com o pensamento de Kayser porque fundamentou sua análise sobre a categoria do grotesco a partir da arte, notadamente da pintura, o que nos autoriza a falar de um grotesco de câmara. Ao analisarmos este conceito segundo Kayser, o grotesco bakhtiniano está intrinsecamente ligado à cultura popular.

Para Bakhtin, as imagens de Rabelais funcionam como herança da cultura cômica popular e servem como distinção das culturas dos séculos precedentes. Essa concepção que segue o princípio material e corporal é batizada por Bakhtin de realismo grotesco.

No realismo grotesco (isto é, no sistema de imagens da cultura cômica popular), o princípio material e corporal aparece sob a forma universal, festiva e utópica. 0 cósmico, o social e o corporal estão ligados indissoluvelmente numa totalidade viva e indivisível. É um conjunto alegre e benfazejo. (BAKHTIN, 2013, p. 17)

O mais importante na concepção do realismo grotesco bakhtiniano é a ideia de rebaixamento, que consiste em trazer para o plano material e corporal, para a terra, 
aquilo que é considerado como elevado, espiritual. Esse valor topográfico perpassa as abordagens que Bakhtin tece sobre a obra de Rabelais. 0 alto e o baixo são, assim, relativos respectivamente ao céu e à terra, e também à cabeça e aos órgãos genitais.

Bakhtin aponta que, para se compreender as concepções de mundo renascentistas, é preciso usar como instrumento o realismo grotesco. 0 corpo grotesco é incompleto, representado pela gravidez, pelo parto, pelo comer e beber e pela satisfação das necessidades naturais, e é também um corpo aberto para o mundo, através dos órgãos genitais, da boca aberta, do falo e do nariz.

Além disso, Bakhtin difere, de forma bastante clara, o grotesco romântico, que buscava aterrorizar, do grotesco realista, integrado à cultura popular "que faz o mundo aproximar-se do homem, corporifica-o, reintegra-o por meio do corpo à vida" (BAKHTIN, 2013, p. 34). Esse realismo grotesco teve seu florescimento na Idade Média, e no Renascimento, seu apogeu.

Ao passar a limpo a tradição do grotesco, apontando textos e pensadores que discorreram sobre o tema, Bakhtin chama atenção ainda para a proximidade entre homem e animal, e para a mudança capital na história do riso, sendo o Renascimento o nó que marca o ápice dessa mudança, pois se até então o riso tinha um papel fundamental na quebra da austeridade social cotidiana, a partir do século XVII o riso não pode ser mais "uma forma universal de concepção do mundo, ele pode referir-se apenas a certos fenômenos parciais e parcialmente típicos da vida social". (BAKHTIN, 2013, p. 57)

Bakhtin critica Hugo que formula o grotesco em oposição ao sublime. Apesar de este ser responsável por uma abordagem pioneira do grotesco, e de ter apontado a existência do grotesco já na Antiguidade, para Bakhtin, Hugo enfraquece o valor autônomo do grotesco, na medida em que o utiliza para a exaltação do sublime. Porém, dentre todos os autores que cita, é mesmo Kayser o que sofre a maior e mais severa crítica.

“A teoria de Kayser é absolutamente inaplicável aos milênios de evolução anteriores ao Romantismo. [...] $\mathrm{O}$ autor nem sequer investiga essas 
manifestações [...]. Tampouco compreende a verdadeira natureza do grotesco" (BAKHTIN, 2013, p. 41).

É importante salientar que rebaixar não significa desabonar ou depreciar, mas antes, assumindo um sentido topográfico, colocar em contato com o baixo, com a terra, com os órgãos genitais e o ventre. O rebaixamento grotesco está ligado ao princípio da vida material e corporal. É importante perceber que não se trata do corpo isolado do mundo. 0 material e corporal assumem um sentido cósmico. Bakhtin salienta que esses elementos não estão ainda singularizados como hoje. Mas é preciso perceber ainda que o princípio da vida material e corporal está ligado ao riso, e não deixa de ser inovador, regenerando a própria vida.

Essa é a qualidade essencial desse realismo, que o separa das demais formas "nobres" da literatura e da arte medieval. O riso popular que organiza todas as formas do realismo grotesco foi sempre ligado ao baixo material e corporal. 0 riso degrada e materializa (BAKHTIN, 2013, p. 18).

Fica claro que, a partir do princípio elementar do rebaixamento, o corpo grotesco é um corpo aberto, incompleto, e os orifícios do corpo ganham destaque significativo. Na cabeça, apenas a boca e o nariz têm importância no desenho do corpo grotesco. São orifícios que ligam o corpo ao mundo. Bakhtin se refere diretamente à importância do nariz e da boca ao discorrer sobre o corpo grotesco. Outro traço característico da imagem grotesca é a animalização. Ao se misturar com o mundo, o corpo grotesco se mistura também com os animais e as coisas. A animalização passa a ser, também, um traço importante dentro do universo grotesco.

Além disso, a comida e o sexo representam uma particularidade da imagem grotesca do corpo, que deglute e vomita. A prática do coito, a absorção de alimentos e a satisfação de necessidades naturais pertencem ainda ao universo de degradações próprias de uma visão grotesca do mundo.

O encontro do homem com o mundo que se opera na grande boca aberta que mói, corta e mastiga é um dos assuntos mais antigos e mais marcantes do pensamento humano. 0 homem degusta o mundo, sente o gosto do mundo, o introduz no seu corpo, faz dele uma parte de si (BAKHTIN, 2013, p. 245).

As características da imagem grotesca nos permitem vislumbrar, com maior nitidez, os traços marcantes do grotesco realista que mais interessa à nossa análise. A 
categoria do grotesco contém, para o bem e para o mal, inúmeras subcategorias que por vezes são até contraditórias. Do Romantismo ao Realismo, o grotesco se deixou infiltrar por tratamentos diversos que partiram sempre de uma mesma essência, de uma premissa que é o caráter estranho e não canônico da imagem grotesca. Mas a partir da especificidade do grotesco realista, abre-se um universo de possibilidades de interpretações que localizam esse grotesco nos mais diversos textos. Se direcionarmos nosso olhar para essas características em determinados filmes, o grotesco surgirá mais vivo diante de nós do que poderíamos supor.

\section{Grande Angular Grotesca.}

Em sua abordagem do grotesco no cinema, Sodré e Paiva partem do geral para o particular, discorrendo, inicialmente, sobre grandes sucessos internacionais, sobretudo o mais óbvio exemplo do grotesco cinematográfico, 0 Homem Elefante (The Elephant Man, de David Lynch, EUA/Inglaterra, 1980), que tem em Monstros ${ }^{6}$ (Freaks, de Tod Browning, EUA, 1932) um desconcertante antecessor. No que concerne ao cinema brasileiro, os filmes citados vão de Carnaval Atlântida (José Carlos Burle; Carlos Manga, 1952) ao tropicalista Macunaíma (Joaquim Pedro de Andrade, 1969).

0 universo almodovariano é apontado por Sodré e Paiva (2002). 0 rebaixamento em Almodóvar daria um trabalho à parte ${ }^{7}$, para além de todos os comentários já feitos aqui. A aquarela kitsch do cineasta sempre coloriu a tela do cinema com a subversão dos bons costumes. Muito antes de Almodóvar, Chaplin já levava o grotesco para as telas, segundo Sodré e Paiva. Com seu personagem Carlitos, Chaplin teria inaugurado o grotesco crítico no cinema através da figura do Palhaço.

Em O Cozinheiro, o Ladrão, sua Mulher e o Amante (The Cook, the thief, his wife and her lover, de Peter Greenaway, Inglaterra, 1989), o grotesco está intensamente presente. E é na figura do ladrão do título que o grotesco se manifesta. Ele é o marido traído, bruto, faminto. No restaurante, ele come e vomita, e persegue o amante de sua

\footnotetext{
${ }^{6}$ Freaks mostra atores com deformidades reais.

7 Um exemplo é O Espetáculo Grotesco nos Filmes de Pedro Almodóvar, de Gabriela Borges da Silva Martins (PUC-SP, 1997).
} 
mulher, referencial da pureza e da beleza clássica, destruído pelo grotesco marido, que mata o amante, mas que, na triunfal vingança da mulher, é obrigado a degustá-lo no banquete final. A mulher, então, abandona seu pedestal neoclássico para enfrentar o marido, seguida de seu séquito, com as mesmas armas que o monstro sempre usara, numa espécie de avesso da sublimação do grotesco. Aqui, é a referência clássica da mulher que se torna grotesca na sequência final.

Ao lado de $O$ Homem Elefante, $O$ Cozinheiro... é um excelente exemplo do grotesco cinematográfico. Mas de que grotesco estamos falando? Construímos os três parágrafos acima com a intenção de promover a mesma confusão que a abordagem de Sodré e Paiva parece fazer. Sem uma definição precisa da aplicação do grotesco a cada filme, não é possível tornar claro com qual grotesco o filme dialoga. Tendo sido esse conceito dividido em subcategorias de matizes tão diversas, é extremamente necessário apontar de que grotesco estamos falando, e a quais variações desse conceito nos remetemos ao aplicá-lo ao cinema.

No filme de David Lynch, o grotesco é concreto e romântico. A deformidade do personagem-título faz com que sua monstruosidade seja motivo de espanto e curiosidade. Aprisionado, o homem elefante chega a ser atração de feiras populares, mas isso não o vincula, de modo algum, ao grotesco realista bakhtiniano. 0 grotesco em $O$ Homem Elefante, então, se enquadra na perspectiva do romantismo. 0 filme trata da sublimação do grotesco. No protagonista, coexistem o monstro, na forma, e o poeta, no conteúdo, como no Quasímodo de Victor Hugo, também adaptado inúmeras vezes para o cinema ${ }^{8}$. É um dos filmes esteticamente mais conservadores de David Lynch, antes da construção definitiva de seu universo onírico, marca de seus filmes mais recentes. $O$ Homem Elefante, portanto, não se filia ao grotesco bakhtiniano.

0 mesmo grotesco encontrado no filme de David Lynch já está presente nos anos 30, em filmes como O Médico e o Monstro (Rouben Mamoulian, EUA, 1931), inspirado no livro de Robert Louis Stevenson, que originou uma série de adaptações

\footnotetext{
8 Dentre as adaptações cinematográficas de 0 Corcunda de Notre Dame, se destacam a de 1939, dirigida por William Dieterle, a de 1982, dirigida por Michael Tuchner, e a animação dos Estúdios Disney de 1996, dirigida por Gary Trousdale.
} 
cinematográficas ${ }^{9}$. Trata-se da história do médico Dr. Jekyll que se transforma em Mr. Hyde. Este tem uma personalidade maligna e passa a ser suspeito de uma série de crimes. 0 médico, então, tem que tomar uma fórmula para permanecer no seu estado original, para que Mr. Hyde não tome conta de sua personalidade. 0 embate entre $o$ bem e o mal nos remete diretamente à obra de Hugo, na deformidade moral do monstro e na retidão do médico, ambos habitando o mesmo corpo, o sublime vivendo no grotesco, bem como dita a regra do grotesco romântico.

Nos anos 40, outra adaptação literária promove mais um importante exemplar do grotesco romântico no cinema. Inspirado na obra de Oscar Wilde, $O$ Retrato de Dorian Gray (The Picture of Dorian Gray, de Albert Lewin, EUA, 1945) tece um embate entre a beleza sublime de Dorian e a perversão moral que faz com que sua imagem reproduzida no quadro, que fora trocado pela sua juventude eterna, torne-se cada vez mais monstruosa. Mais uma vez, a dualidade do sublime e do grotesco está presente, reverberando no cinema os ideais do grotesco romântico que Hugo conceituou.

Ao contrário dos exemplos acima, o grotesco bakhtiniano poderá ser encontrado, por exemplo, a partir dos anos 50, no musical Entre a Loura e a Morena (The Gang's all here, de Busby Berkeley, EUA, 1943). 0 exagero das bananas gigantes, fálicas, do antológico número musical pelo qual o filme ficou conhecido, o rebaixamento da personagem vivida por Carmem Miranda, sempre com um apetite sexual exagerado, tudo parece indicar que o grotesco realista se instaurou de forma elementar em alguns filmes hollywoodianos. Mas foi nas cinematografias nacionais, em obras de cineastas de renome como Federico Fellini e Píer Paolo Pasolini, que o grotesco realista atingiu seu auge na tela. Surgidos no seio do movimento neorrealista ainda como roteiristas, Fellini e Pasolini acabaram dirigindo, respectivamente, obras maiores como, Noites de Cabíria (Le Notti di Cabiria, Itália, 1957) e Mamma Roma (Itália, 1952), e levaram seu cinema para outro campo, o do grotesco, presente com maior ou menor intensidade em várias de suas obras.

\footnotetext{
${ }^{9}$ O livro suscitou diversas adaptações, sendo as mais expressivas, além da já citada, a de 1941, dirigida
} por Victor Fleming, e a de 1996, dirigida por Stephen Frears com o título Mary Reilly. 
A menção que Sodré e Paiva fazem ao cinema de Pasolini se restringe a Saló, os 120 dias de Sodoma (Salò o le 120 giornati di Sodoma, Itália, 1975), mas poderia ser acompanhada de outros títulos do mesmo diretor, afinal, Pasolini utilizou intensamente o grotesco cinematográfico. Em Saló, o grotesco está presente na premissa do filme e na obra que o originou ${ }^{10}$. Um grupo de homens se isola num castelo onde serão experimentados de forma exacerbada os prazeres do corpo. Para isso, raptam jovens que lhes servirão de objetos sexuais, estupram, matam, e chegam aos limites do rebaixamento grotesco ao servirem um banquete de fezes aos prisioneiros sexuais. Um dos filmes mais escatológicos da história do cinema, Saló afirma a tendência grotesca de Pasolini, o que é ratificado em outros filmes.

Um dos melhores momentos do grotesco realista em Pasolini pode ser encontrado no filme em episódios RoGoPaG ${ }^{11}$ (Itália, 1962). No trecho dirigido pelo cineasta, atores encenam a Paixão de Cristo. Equipe e elenco, em volta da cruz, reclamam sem parar, riem, têm vontade de urinar. Pasolini desconstrói e profana o sagrado, colocando o rebaixamento grotesco em primeiríssimo plano, subversão que chega ao extremo na chamada Trilogia da vida, formada por Decameron (Il Decameron, Itália, 1970), Contos de Canterbury (Il Raconti di Canterbury, Itália, 1971) e As Mil e Uma Noites (Il Fiori dele mille e una notte, Itália, 1974).

Sodré e Paiva (2002) citam Roma (Itália, 1972) e E La Nave Va (Itália, 1983), de Fellini, indicando-os como representantes do grotesco cinematográfico, mas deixam de fora o mais grotesco de seus filmes, Satyricon (Itália, 1969). Este e outros filmes são fundamentais para se compreender o grotesco felliniano, especificamente e o grotesco cinematográfico, em geral, permanecem ausentes da análise desses autores. Em Fellini, a profanação está sempre presente, em maior ou menor grau, mas em filmes como Roma e Satyricon, o mestre italiano conseguiu destilar de forma mais aguda o rebaixamento grotesco com que habitualmente trabalhava.

\footnotetext{
${ }^{10}$ Saló é inspirado num livro do Marquês de Sade.

11 Os outros episódios foram dirigidos por Rossellini, Godard e Ugo Gregoretti, daí o título RoGoPaG, que são as iniciais dos diretores dos episódios.
} 
$\mathrm{Na}$ verdade, o rebaixamento grotesco sempre esteve na ordem do dia para Fellini. Em Amarcord (Itália, 1974), o patriarca da família faz exercícios em torno da mesa de jantar, flexiona os joelhos e solta sonoros gases perante a família. Mas a sequência tem uma leveza pueril, marca de muitos de seus filmes. Ainda em Amarcord, é preciso lembrar o antológico encontro entre o jovem Titta e a obesa dona do armazém, no qual Titta é assediado por ela e se vê afogado em seus volumosos seios. 0 tom de humor se afasta ,consideravelmente, da irreverência agressiva de Pasolini, mas ambos seguem de perto o princípio do material e corporal, colocando o rebaixamento grotesco em lugar privilegiado.

Ainda nos anos 70, um dos mais polêmicos filmes dentro do registro do rebaixamento grotesco foi realizado. Trata-se de A Comilança (La Grande abbuffata, de Marco Ferreri, Itália, 1973), no qual quatro homens decidem ir para uma mansão na qual pretendem comer até morrer. 0 exagero dessa premissa já seria o suficiente para enquadrá-lo dentro dos parâmetros do grotesco realista. 0 mais impressionante é que eles levam ao limite essa proposta inicial, fartando-se de comida e sexo até a morte. Aqui, a comida e o sexo são colocados no mesmo plano. Princípio do grotesco realista, tudo isso é tratado como uma coisa só: o rebaixamento promovido liga o homem à terra, a vida à morte, a comida ao sexo. A Comilança tem um ponto de partida parecido com o de Saló, de Pasolini, mas as estratégias de cada diretor diferem cada um imprime sua marca ao grotesco realista no cinema.

Para continuar localizando o grotesco cinematográfico, é interessante abordar, também, aos filmes do grupo Monty Python. Em O Sentido da Vida (Monty Python's The Meaning of life, de Terry Gilliam, Inglaterra, 1983), filme dividido em esquetes, um homem artificialmente gordo está à mesa de um restaurante e faz seu pedido ao garçom. Com baldes ao seu lado, ele vomita para poder comer mais. A radicalização da gula leva o homem a explodir no final do esquete, restando um improvável esqueleto gigante à mesa. A filmografia do grupo é rica em exemplos.

Voltando ao grotesco romântico, será nos anos 80 que David Cronenberg construirá seu universo fílmico, utilizando-se dessa categoria estética. Seu cinema, 
como apontam Sodré e Paiva (2002), transita entre a fantasia científica, o terror e o grotesco. Os filmes citados por esses autores são os mais conhecidos: $A$ Mosca (The Fly, EUA, 1986), Gêmeos, Mórbida Semelhança (Dead Ringers, EUA, 1988), Crash (EUA, 1996). Porém, talvez o mais grotesco em Cronenberg seja Mistérios e Paixões (Naked lunch, EUA, 1991). Delírios, drogas e monstros num filme tão sombrio quanto enigmático, fruto da difícil adaptação do conto no qual se origina ${ }^{12}$. Videodrome (EUA, 1982), outro filme de Cronenberg, também segue a linha dos títulos acima e tem sempre a intenção de horrorizar.

Assim, entre filiações ao grotesco romântico e ao grotesco realista, o cinema construiu uma tradição considerável de filmes que se ligam a essas categorias. Vale a pena, ainda, elencar alguns filmes brasileiros importantes para uma reflexão sobre o grotesco cinematográfico. 0 melhor exemplo talvez seja Bocage, o triunfo do amor (Djalma Limonje Batista, Brasil, 1997). Nele, o rebaixamento material e corporal se funde com a narrativa poética sobre o grande nome da literatura lusa. A questão do sexo é colocada em primeiro plano e o filme segue, esteticamente, essa premissa. 0 corpo nu do personagem principal, a poesia de Bocage, tudo comunga para que o grotesco realista seja mais uma vez salientado na tela.

Na década anterior, podemos destacar A Marvada Carne (André Klotzel, Brasil, 1986). A propósito do que Bakhtin relata sobre a importância do nariz como uma imagem grotesca, é relevante destacar a sequência em que um dos personagens corta, acidentalmente, o nariz do outro e, como solução para encontrar o nariz cortado, espalham um pó que provoca espirros, possibilitando a localização da parte do corpo perdida. No chão, o nariz espirra sem parar. Na sequência seguinte, o nariz é recolocado no seu lugar, só que na posição invertida. Outros causos em A Marvada Carne garantem a classificação deste como um dos melhores exemplos do grotesco cinematográfico no cinema brasileiro.

Nessa lista não pode faltar Macunaíma, que citamos anteriormente. 0 filme é um marco do cinema brasileiro e utiliza-se, intensamente, dos princípios do grotesco

120 filme é adaptado do livro The Naked Lunch, de William S. Burroughs. 
realista. É a própria imagem de herói que é rebaixada. Macunaíma, o herói sem nenhum caráter, parte em sua jornada, conectado à terra e aos homens através do princípio do material e corporal. Joaquim Pedro foi, sem dúvida, um dos diretores brasileiros que mais contribuíram para a construção de uma tradição do cinema infiltrado pelo grotesco no Brasil.

Mas o leque de filmes brasileiros que se utilizam de recursos próprios do grotesco realista vai muito além. As irmãs mineiras de Amélia (Ana Carolina, 2000), os pelos no rosto de Carlota Joaquina (Carla Camurati, 1995), ou mesmo o já comentado exotismo de Carmem Miranda, que em sua incursão hollywoodiana aparecia sempre encarnando a personagem mais liberada em termos sexuais, promovendo uma verdadeira revolução nas partes baixas, na acepção de Bakthin, montam um painel do grotesco cinematográfico que, de certa forma, escapa à abordagem contida em $O$ Império do Grotesco, de Sodré e Paiva. Além disso, não se pode negar a relevância do cinema erótico como representativo do grotesco cinematográfico. No Brasil, após uma larga tradição de pornochanchadas, o cinema erótico aparece na década de 90, sobretudo nas produções de Custódio Gomes, em filmes como As Aventuras Eróticas de Dick Traça e Alucinações Sexuais de um Macaco, ambos de 1991. No entanto, esse cinema vai sendo paulatinamente, ao longo da década de 90, convertido para o mercado de vídeo.

O cinema erótico brasileiro conhece, também, outra vertente, na qual podemos destacar, por exemplo, Dona Flor e Seus Dois Maridos (Bruno Barreto, 1976), em que a relevância da comida e do sexo pode ser tomada como norte do filme. Dona Flor se entrega ao fantasma de seu falecido marido com o mesmo apetite com que ensina receitas típicas da cozinha baiana, unindo os prazeres do sexo e da comida.

Seja como for, o grotesco cinematográfico está presente, em maior ou menor grau, em diversos gêneros e vertentes do cinema nacional e estrangeiro. 0 que interessa aqui é afirmar que, para além do esforço em listar filmes de diversas nacionalidades, nem sempre a indicação do conceito do grotesco no cinema, e nas outras artes, sustenta a ausência de uma taxonomia mais precisa. Como exemplo, $O$ 
Homem Elefante segue os cânones do grotesco romântico e não tem nada de grotesco realista, categoria trabalhada por Bakhtin. É preciso que os teóricos sinalizem qual categoria de grotesco estão manuseando, sob pena de construírem uma argumentação que não ajuda no avanço da conceituação do grotesco.

\section{Considerações finais}

O grotesco sempre marcou presença na arte, porém, enquanto conceito, foi preciso esperar o Romantismo do século XIX para que o mesmo se desenvolvesse com maior vigor. As contribuições decisivas para isso foram os escritos de Victor Hugo e sua conceituação do grotesco e do sublime. Depois, foi a vez de Wolfgang Kayser e seu grotesco de câmera e, sobretudo, de Mikhail Bakhtin, que inaugurou uma nova vertente para se pensar o conceito, a saber, o realismo grotesco.

As ideias centrais do Rebaixamento, do princípio do material e do corporal e do corpo grotesco nos ajudam a visualizar um novo universo de imagens através do ideário bakhtiniano. A partir dessa nova vertente, o conceito de grotesco merece ser sempre adjetivado, para que se possa apontar, com mais precisão, qual a natureza do grotesco a que a obra de arte está vinculada.

No cinema, são muitos os exemplos de cenas que nos autorizam a vincular um filme a determinada vertente, seja o grotesco romântico, seja o grotesco realista. No entanto, nem sempre as abordagens decorrentes de estudos centrados em análise fílmica se preocupam em sinalizar qual grotesco está sendo aplicado. Sendo assim, repassar o conceito desde suas origens é salutar para decantarmos com mais clareza quando um filme se vincula a uma ou outra vertente.

O cinema grotesco é uma realidade e os exemplos que evocamos são prova cabal disso. Assistir a esses filmes tendo o grotesco como chave de leitura nos abre inúmeras possibilidades de análise, enriquecendo o repertório do cinema, de uma maneira geral, com a categoria do grotesco e, de modo particular, com o ideário bakhtiniano, através da noção de rebaixamento e colorindo os filmes com novas possibilidades de visionamento. 


\section{REFERÊNCIAS}

ALMEIDA, Jayme de. Marvada carne: uma comédia caipira. In: SOARES, Mariza de Carvalho e FERREIRA, Jorge. A História vai ao cinema: vinte filmes comentados por historiadores. Rio de Janeiro: Record, 2001.

BAKHTIN, Mikhail. A cultura popular na Idade Média e no Renascimento. 0 contexto de François Rabelais. São Paulo: HUCITEC; [Brasília]: Editora da Universidade de Brasília, 2013.

HUGO, Victor. Do Grotesco ao Sublime. (Tradução do "Prefácio de Cromwell”). São Paulo: Editora Perspectiva, 1988.

KANT, Immanuel. Crítica da faculdade do juízo. Rio de Janeiro: Forense Universitária, 1993.

KAYSER, Wolfgang. 0 Grotesco. São Paulo: Editora Perspectiva, 1986.

KOTHE, Flávio R. Paródia \& cia. In: Revista Tempo Brasileiro, n.62, 1980.

LACOSTE, Jean. A Filosofia da Arte. Rio de Janeiro: Jorge Zahar Editor, 1986.

SODRÉ, Muniz e PAIVA, Raquel. 0 Império do Grotesco. Rio de Janeiro: Mauad, 2002.

SODRÉ, Muniz. A Comunicação do Grotesco. Rio de Janeiro: Editora Vozes, 1972.

STAM, Robert. Bakhtin, da teoria literária à cultura de massa. São Paulo: Ática, 1992.

VAINFAS, Ronaldo. Carlota: caricatura da História. In: SOARES, Mariza de Carvalho e FERREIRA, Jorge. A História vai ao cinema: vinte filmes comentados por historiadores. Rio de Janeiro: Record, 2001. 